
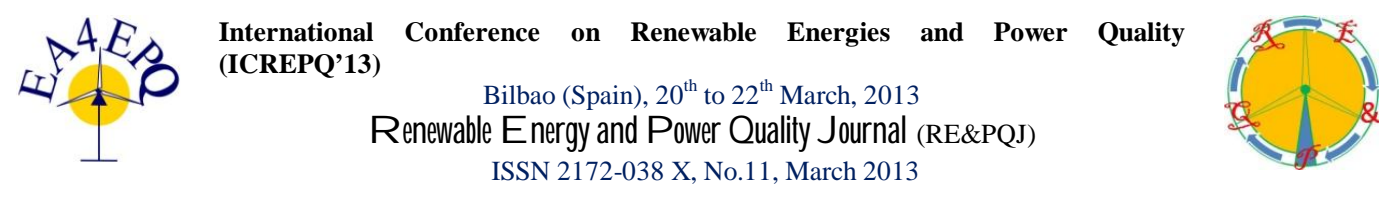

\title{
Financial Analysis for a Multi-Carrier Energy System Equipped with CCHP
}

\author{
A. Sheikhi ${ }^{1}$, Sh. Bahrami ${ }^{2}$, A.M. Ranjbar ${ }^{3}$, S. Sattari ${ }^{4}$, M. Adami ${ }^{5}$ \\ ${ }^{1,2,3,5}$ Department of Electrical Engineering, ${ }^{4}$ Department of Energy \\ Sharif University of Technology \\ Tehran, Iran \\ ${ }^{1}$ Phone/Fax number: +989126613840, e-mail: 1'sheikhi@ee.sharif.edu, Shahab_bahrami@yahoo.com, \\ 2amranjbar@sherif.edu, ${ }^{3}$ sattari@iies.net, ${ }^{5}$ adami@ee.sharif.edu
}

\begin{abstract}
The interest on distributed generation has been increasing in recent years, especially due to technical development on generation systems that meet environmental and energy policy concerns. One of the most important distributed energy technologies is Combined Cooling, Heat and Power (CCHP) systems. CCHP is a small and self-contained electric, heating and cooling generation plant that can provide power for household applications, commercial or industrial facilities. It can reduce power loss and enhance service reliability in distribution systems.

Since the input of a CCHP system is natural gas then natural gas price is so important in CCHP penetration level in DG's market.

In this paper authors by considering gas price, capital cost and also sales revenue, find the effects of these parameters in financial parameters for a multi-carrier energy system with optimal size and operation by applying COMFAR III software.
\end{abstract}

\section{Key Words}

Combined cooling heating and power (CCHP), energy hub, financial analysis, sensitivity analysis, internal rate of return (IRR), Net present value (NPV), payback period

\section{Introduction}

The electric power industry is under deregulation in response to changes in legislation, technology, market and competition. One of the main advantages of deregulation is that it can increase the efficiency of industrial and commercial sectors and reduce the cost of electrical energy for all customers [1].

Deregulation has evolved in all three sectors of the power system (i.e. generation, transmission, and distribution) from centralized to a decentralized status. One of the main concepts in deregulation is Microgrids which are used at the distribution level [2]. Microgrid, with its decentralized electricity generation, combined with onsite production of heat, could provide reliable and electric power as well as heat and cooling to its consumers at an economic cost. Nowadays, following the expansion of natural gas networks and also benefits of this energy carrier such as lower emission level and its prices, CCHP technologies have attained unprecedented level of popularity as one of the most important distributed energy resources $[3,4]$.

Natural gas price is another main factor that has a significant effect on the CCHP penetration level as a DG [5].

Generally, an optimized CCHP can be evaluated by analyzing two main factors: costs and benefits. Cost is one of the main components in nearly all DG financial analysis, but is inadequate for complete evaluations. Furthermore, reliability enhancements [6], power cost saving, power loss and emission reduction [7] are also key elements in deciding which CCHP should be installed. 
The cost of generation of electricity, heat and cooling from a CCHP can be classified into capital investment cost, operation and maintenance (O\&M) costs, fuel cost and depreciation cost. On the other hand, the benefits from the CCHP placement can be classified into power loss reduction, low electricity, heating and cooling price generated by CCHP and significantly decreasing the expected energy not supplied which is a favorable effect in a power system $[6,7]$.

CHP can inject its power directly into distribution feeders and by alleviating transmission losses the benefits of power loss reduction become quite clear [7, 8, 9]. Moreover, reliability enhancement has received substantial attention as it reduces the costs of losses incurred by utility customers as a result of power failures [10].

All of these costs and benefits are calculated and accumulated over the economic life of the respective equipment. It is common practice for a decision maker to translate future cash flows into their present values [9].

The contents of this paper are organized into the following five sections. After the introduction in section I, the energy hub concept and a brief overview of the Energy hub modeling is presented in Section III. Section IV gives the brief definition of financial parameters and then in section $\mathrm{V}$ results and sensitivity analysis are depicted. Finally the conclusions are drawn in section VI.

\section{Energy Hub Concept and Modeling}

Some conceptual approaches for an integrated view of transmission and distribution systems with distributed generation have been published. Besides "energy services supply systems" [10], "basic units" [11], and "micro grids" [12], so-called "hybrid energy hubs", are suggested, where the term "hybrid" represent the use of multiple energy carriers [13, 14]. An energy hub is considered a unit where different energy carriers can be converted, conditioned, and maybe stored. It represents an interface between different energy infrastructures and/or loads. Energy hubs consume power at their input ports which is connected to, e.g. electricity and natural gas infrastructures, and perform certain required energy services such as electricity, heating, cooling, and compressed air at their output ports [4].

Energy hubs include two basic elements: direct connections and converters. Direct connections are used to deliver an input power to the output without converting. Converter elements are used to change carriers into other forms or qualities. Such as gas turbines, combustion engines or fuel cells. Figure 1 demonstrates an example of an energy hub.

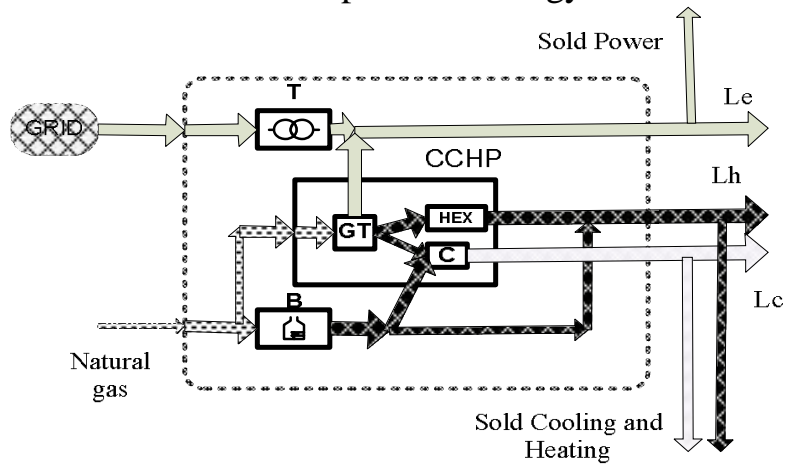

Fig. 1. An energy hub containing an electric transformer, a CHP, a boiler (B), an absorption chiller (C) and Heat Exchanger (HEX)

The components within the hub may create extra connections between inputs and outputs. For instance, the electrical load connected to the hub in Figure 1 can be met by consuming all power directly from the electricity grid or generating part or all of the required electricity from natural gas. This redundancy in supply results in a significant benefit, which can be achieved using energy hubs: Reliability of supply can be enhanced from the load's perspective because it is not completely dependent on a single supply.

From a system point of view, combining and coupling different energy carriers show a number of potential benefits over conventional, decoupled energy supply.

The energy hub is an archetype with no limitations to the size of the modeled system. Single power plants or industrial buildings as well as bounded geographical areas such as entire towns can be modeled as energy hubs. The model of the system is formulated below.

In the system under study, the energy hub represents a general consumer as a household which uses both electricity and gas. The hub is connected to a large gas network and the electricity network.

The hub consumes electric power $\mathrm{P}_{\mathrm{e}}$ and gas $\mathrm{P}_{\mathrm{g}}$ and provides energy to its electric load $\mathrm{L}_{\mathrm{e}}$, heating load $\mathrm{L}_{\mathrm{h}}$ and cooling load $\mathrm{L}_{\mathrm{c}}$. The hub contains conversion technologies in order to fulfill their energy load requirements. For energy conversion, the hub contains a CCHP and an auxiliary boiler. The CCHP device couples the three energy systems at the same time that produces electricity, cooling and heat from natural gas. Depending on the prices of energy and load profiles, the CCHP device is utilized differently. At high electricity prices, the electric load is supplied by CCHP for longer times. The produced heat is then used to supply the thermal load. At low electricity prices, the electric load is rather supplied directly by the electricity network and the gas is used for 
supplying the thermal load via the boiler house. Hence, there are several ways in which electric and thermal load demands can be met. This redundancy increases the reliability of supply overtly and simultaneously provides the possibility for optimizing the input energies, e.g. using criteria such as cost, availability, emissions, etc.

Consider a converter device as depicted in Fig (2) that converts an input energy carrier $\alpha$ into $\beta$. Input and output power flows are not independent; they are considered to be coupled,

$$
\mathrm{L}_{\beta}=\mathrm{c}_{\alpha \beta} \times \mathrm{P}_{\alpha}
$$

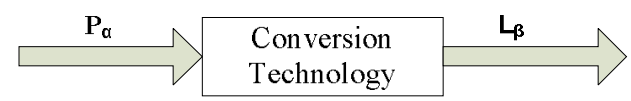

Fig. 2. Model of energy converter

where $\mathrm{P}_{\alpha}$ and $\mathrm{L}_{\beta}$ are the steady state input and output energy flows respectively, $c_{\alpha \beta}$ is the coupling factor which defines the coupling between input and output energy flow. For a simple converter device with one input and one output, the coupling factor corresponds to the converter's steady state energy efficiency.

A general model covering all types of couplings can be stated all power inputs $\mathrm{P} \alpha, \mathrm{P} \beta, \ldots, \mathrm{P} \omega$ and outputs $\mathrm{L}_{\alpha}$ $, \mathrm{L}_{\beta}, \ldots, \mathrm{L}_{\omega}$ in vector form and enables the formulation of a multi-input, multi-output power conversion as follow $[4,9]$ :

$\left[\begin{array}{l}\mathrm{L}_{\alpha} \\ \mathrm{L}_{\beta} \\ \cdot \\ \cdot \\ \cdot \\ \mathrm{L}_{\omega}\end{array}\right]=\left[\begin{array}{llllll}C_{\alpha \alpha} & C_{\beta \alpha} & \cdot & \cdot & \cdot & C_{\omega \alpha} \\ C_{\alpha \beta} & C_{\beta \beta} & \cdot & \cdot & \cdot & C_{\omega \beta} \\ \cdot & \cdot & \cdot & & \cdot \\ \cdot & \cdot & & \cdot & \cdot \\ \cdot & \cdot & & \cdot & \cdot \\ C_{\alpha \omega} & \cdot & & & & C_{\omega \omega}\end{array}\right]\left[\begin{array}{l}\mathrm{P}_{\alpha} \\ \mathrm{P}_{\beta} \\ \cdot \\ \cdot \\ \cdot \\ \mathrm{P}_{\omega}\end{array}\right]$

(2)

Aras Sheikhi in [15-17] found the best size for an energy hub system by employing this model.

\section{System Description}

Three types of energy flow are present in the system: electrical energy, heating and cooling. It is supposed that the system has been connected to the grid and any power supply shortages should be compensated by the grid. The management strategy of this system is only from producer's point of view. The grid is the customer for electricity which can purchase the power produced by this system. Heating and cooling that are produced by CCHP met the thermal demand of the energy hub.

Although the system can have other CHP types, it is supposed that the CHP is a reciprocating engine coupled with a generator that produces power and hot water. It is assumed that all pipes and thermal storage tank have been highly insolated, but there may be little waste heat form CHP. Absorption chiller converts the recovered heat to the cooling that meets the cooling load.

\section{Optimal Operation for Trigeneration System}

The essential point in optimal operation is technoeconomic aspect of operation. The importance of optimal operation originates from our need to invest lower, save money, time, fossil fuels, and environment, and gain more benefit and comfort.

Optimization of above parameters has a significant effect on overall efficiency of energy hub and decrease the operational cost apparently.

To investigate optimized value of these parameters, the following objective function has to be minimized which is considered the total energy cost for the energy hub system:

Min $\left\{\right.$ runing $\cos t=\sum_{n=1}^{48}\left(P_{e}(n)-k k(n)\right) \times e(n)+P_{g}(n) g(n)$
$\left.+P_{e}(n) \chi_{e}+P_{g}(n) \chi_{g}\right\}$
$L_{e}+k k=\eta_{e e} P_{e}+\gamma \eta_{g e}^{C H P} P_{g}$
$L_{h} \leq\left((1-\gamma) \alpha \eta_{g h}^{B}+\gamma \eta_{g h}^{C H P} \beta\right) P_{g}$
$L_{c}=\left((1-\gamma)(1-\alpha) \eta_{g h}^{B}+\gamma \eta_{g h}^{C H P}(1-\beta)\right)$
$\times \eta^{\text {chiller }} P_{g}$
$P_{g}^{\min } \leq P_{g} \leq P_{g}^{\text {Max }}$
$P_{e}^{\text {min }} \leq P_{e} \leq P_{e}^{\text {Max }}$
$k k \leq P_{s e M}$
$0 \leq \gamma \leq 1$
$0 \leq \beta \leq 1$
$0 \leq \alpha \leq 1$

Today the threat of global warming and climate change has created worldwide concerns. As a result many countries reached and signed agreements such as Kyoto in order to reduce greenhouse gas emissions. Hence, $\mathrm{CO}_{2}$ emission consideration is highlighted as one of the effective factors on power generation. Based on the social costs of carbon emissions, assuming that the price of carbon is around $\$ 30(\mathrm{US})$ per ton $(0.03 \$$ per $\mathrm{Kg})$ which needs to increase with inflation rates [18].

Note that the feasible region of the optimization problem is defined by different constraints. An equality constraint is given by the equation that describes the power flow through the hub. Inequalities arise from limitations of the hub's input power vector and the power inputs to the individual converters. The relation between the hub input vector and the converter input vector is given (4), (5) and 
(6). Lower and upper limits of CCHP and transformer rates are defined as (7) and (8) respectively. Maximum electricity that could sell to the grid is shown in (9). Limitation of the dispatch factors, (10), by zero and one has to be regarded as well.

\section{Financial Parameters Definition}

The financial analysis of investment projects is typically carried out using the technique of discounted cash flow (DCF) analysis. This section introduces concept of DCF analysis for the derivation of project performance criteria such as net present value (NPV) and internal rate of return (IRR).

Discounted Cash Flow (DCF) analysis is the technique used to derive financial performance criteria for investment projects. Cash flow analysis is simply the process of identifying and categorizing of cash flows associated with a project or proposed course of action, and making estimates of their values.

Discounted cash flow analysis is an extension of simple cash flow analysis and takes into account the time value of money. A number of criteria are used in DCF to estimate project performance including Net Present Value (NPV), and Internal Rate of Return (IRR) and Dynamic Payback Period (DPP) [19].

\section{A. Net present value}

The net present value (NPV) is the sum of the discounted annual cash flows.

$$
\mathrm{NPV}=\sum_{\mathrm{T}=1}^{\mathrm{E}} \frac{\mathrm{a}_{\mathrm{T}}}{(1+\mathrm{ir})^{\mathrm{T}}}
$$

A project is regarded as financially desirable if the NPV is positive [20].

\section{B. Internal rate of return}

The internal rate of return (IRR) is the interest rate such that the discounted sum of net cash flows is zero.

Generally speaking, the higher a project's internal rate of return, the more desirable it is to undertake the project. As such, IRR can be used to rank several prospective projects a firm is considering. Assuming all other factors are equal among the various projects, the project with the highest IRR would probably be considered the best and undertaken first [21].

The value of IRR such that $\sum_{T=1}^{E L} \frac{a_{T}}{(1+I R R)^{T}}=0$

\section{Dynamic Payback period}

The dynamic payback period (DPP) is the number of years for the projects to break even, i.e. the number of years for which discounted annual net cash flows must be summed before the sum becomes positive (and remains positive for the remainder of the project's life). The dynamic payback period indicates the number of years until the investment in a project is recovered. It is a useful criterion for a firm with a short planning horizon, but does not take account of all the information available, i.e. the net cash flows for years beyond the payback period $[20,21]$.

\section{Case Study}

Data for CCHP specifications for a hotel in Tehran have been considered in Table I. The loads data and electricity and gas price in Tehran are depicted in figures (3-6). [22], [15-17].

Table I. CCHP Specifications

\begin{tabular}{|c|c|c|c|c|c|}
\hline $\begin{array}{c}\text { Maintenance } \\
\text { Cost }(\$ / \mathrm{kWh})\end{array}$ & $\eta_{g e}^{C H P}$ & $\eta_{g h}^{C H P}$ & $\eta_{g h}^{B}$ & $\eta_{e e}$ & $\eta^{\text {chiller }}$ \\
\hline 0.01 & $35 \%$ & $40 \%$ & $90 \%$ & $98 \%$ & $60 \%$ \\
\hline
\end{tabular}

Hotels usually operate 7,800 to 8,760 hours yearly. Most hotels, particularly larger ones, have considerable annual electricity consumptions. They also have high thermal needs [7]. This translates into a high thermal to electrical ratio of about 1.2 for the average hotel [7, 22], indicating hotels can beneficially recapture waste heat generated by a CHP system. The high number of operating hours and the rather constant electrical, heat and cooling loads make hotels suitable candidates for a CCHP system.

In this case study, operational costs of a $5,000 \mathrm{~m}^{2}$ hotel as an energy hub is calculated and used to self best CCHP system operation.

The problem solved by nonlinear solvers. In this paper, GAMS was used as a solver. The loads data are depicted in figures (3-6). Note that in figure (4) there are two load profiles. One of them denotes winter and autumn day load sample and the other indicates load profile of summer and spring days.

System major components and their capacities are as follows.

1) CHP: $1 \mathrm{MW}$ (electrical)

2) Auxiliary boiler: $220 \mathrm{~kW}$

3) Absorption chiller: $785 \mathrm{~kW}$

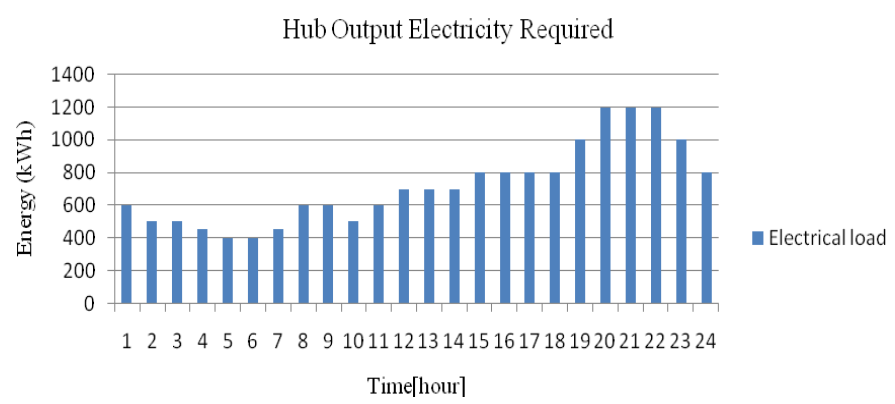

Fig. 3. Electricity consuption in a normal day[summer and winter] 


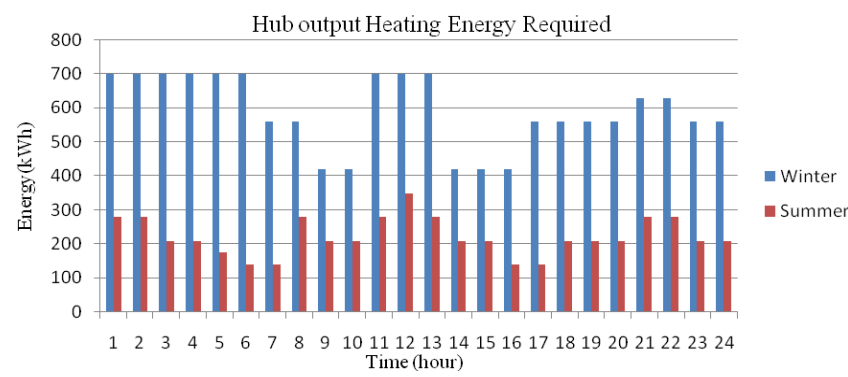

Fig. 4. Heating Energy consuption in a normal day[summer and winter]

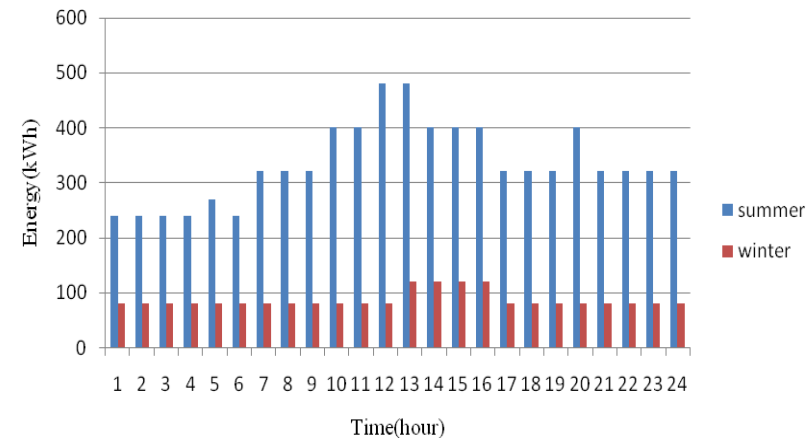

Fig. 5. Cooling Energy consuption in a normal day[summer and winter]

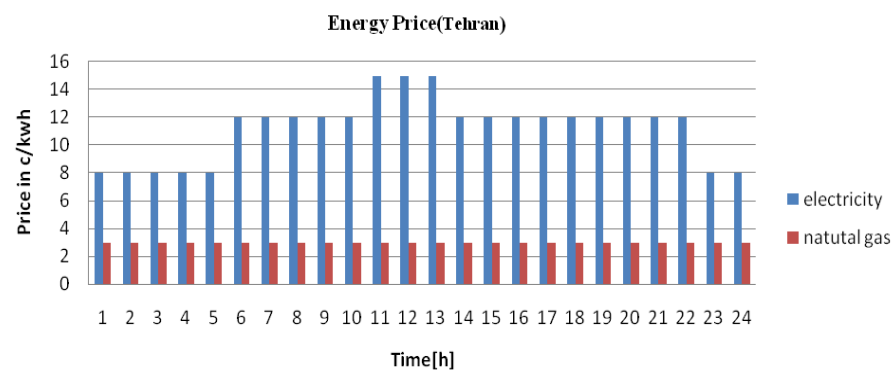

Fig. 6. Energy price

In this case since extra recovered heat could not be sold, the extra heat is passed to heat dump radiator. The heat dump radiator is cooled by electrically driven fans.

In this study, all efficiencies are independent of power and have a constant value [23]. The typical energy distribution for internal combustion engines is provided $[24,25]$. It shows that $30 \%$ of the fuel energy is converted to heat energy rejected through the coolant and another $30 \%$ of the fuel energy is rejected as heat through the exhaust gas. The total efficiency of heat exchangers for the coolant and exhaust gas is estimated to be 0.85 , and the total fuel-to-thermal-energy conversion efficiency (i.e., total heat recovered from the engine) is then calculated to be $(30 \%+30 \%)(0.85)=51 \%$.

The boiler thermal efficiency $\left(\eta_{\mathrm{gf}}\right)$ is assumed to be $90 \%$. The total efficiency of the cooling components (chiller efficiency) was estimated by considering the
Coefficient of Performance (CoP), amount of heat moved per unit of input work required, of an absorption chiller and the efficiency of an air handling unit.

A CoP of 0.7 is used for the absorption chiller and an efficiency of 0.85 is used for the air handling unit. The total efficiency of cooling components is then calculated to be $(0.7) \times(0.85) \times 100=60 \%$. The total efficiency of the heating components is estimated at $85 \%$ which is the efficiency of the air handling unit.

The thermal energy losses due to energy transport/transmission in the network are neglected in this simulation because the pipes are well insulated in the facility.

For Tehran $X_{\mathrm{e}}=1.32 \$ / \mathrm{kWh}$ and $\mathrm{X}_{\mathrm{g}}=0.6 \$ / \mathrm{kWh}[26$, 28]. Figures 7 to 10 show results of the optimization problem.

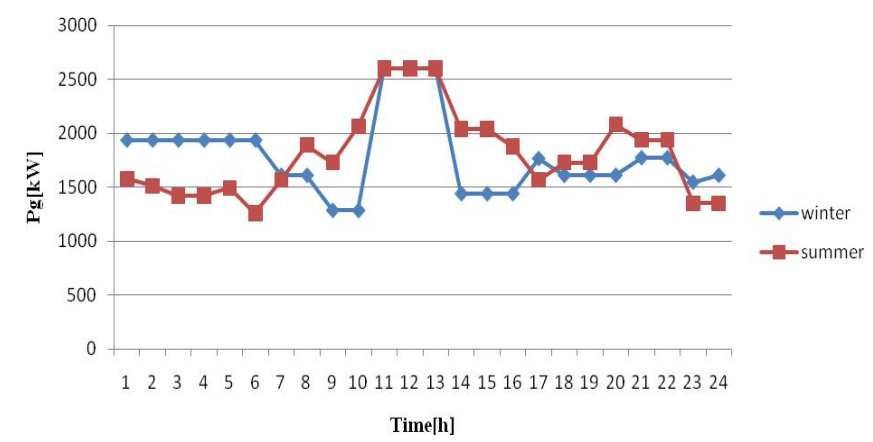

Fig. 7. Input natural gas $\left(\mathrm{P}_{\mathrm{g}}\right)$

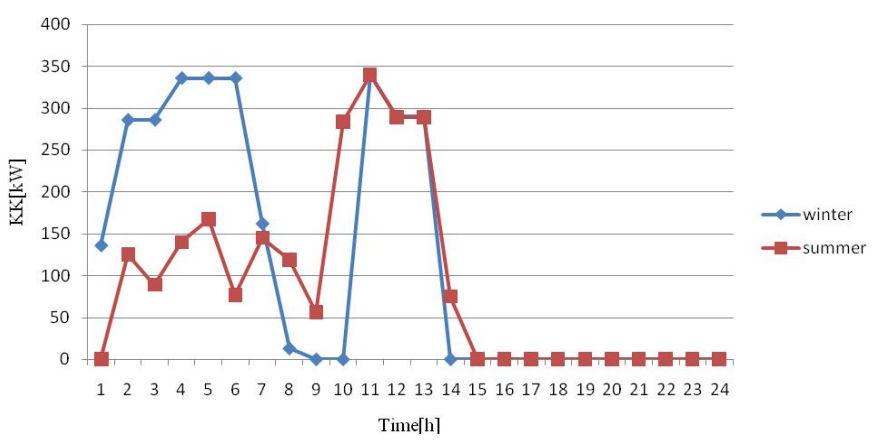

Fig. 8. Exported electricity to the grid

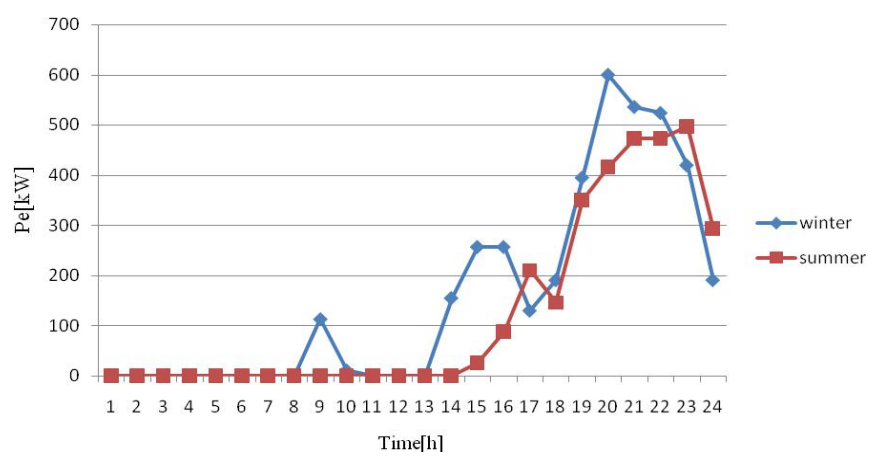

Fig. 9. Imported electricity from the grid 


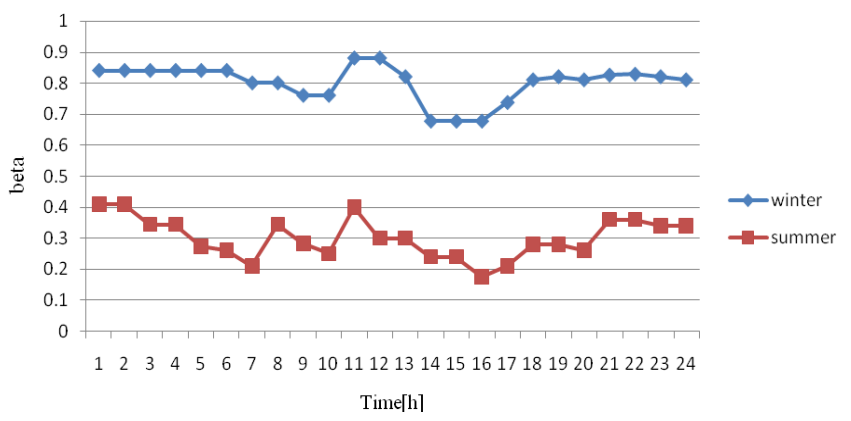

Fig. 10. Dispatch factor for $\mathrm{CHP}(\beta(\mathrm{N}))$

By these considerations and also the capital cost that is around 1.5 million dollars (This price consists of CHP, absorption chiller and heating storage) by applying COMFAR III economic parameters are calculated.

Figures 11 and 12 show the sensitivity analysis for IRR and NPV. Table II lists the economic results of implementing optimized energy hub's elements in the hotel in Tehran.

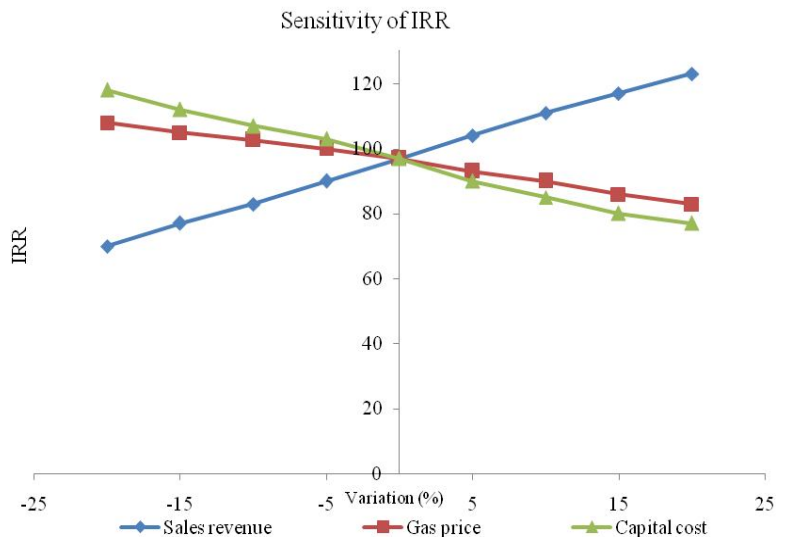

Fig. 11. Sensitivity of IRR

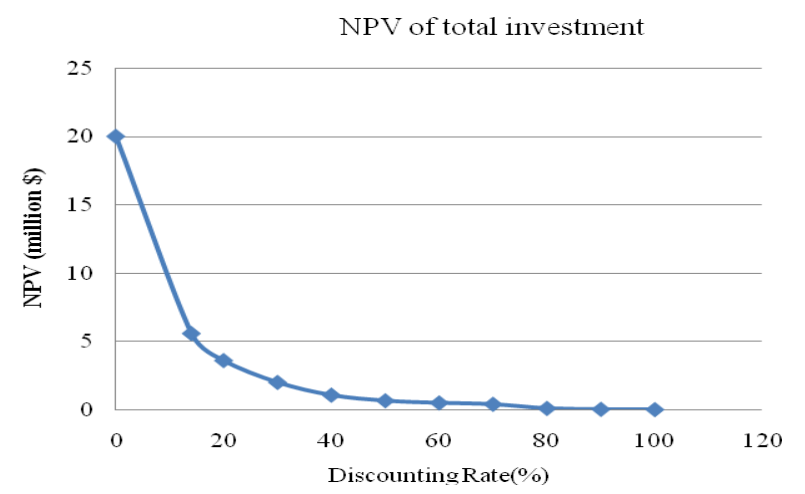

Fig. 12. Sensitivity of NPV

Table II. Parameters Results

\begin{tabular}{|c|c|c|}
\hline $\begin{array}{c}\text { Internal Rate of } \\
\text { Return (IRR(\%)) }\end{array}$ & $\begin{array}{c}\text { Net Present Value } \\
(\mathrm{NPV}(\text { million \$)) }\end{array}$ & $\begin{array}{c}\text { Dynamic Payback } \\
\text { Period (DPP(year)) }\end{array}$ \\
\hline $97 \%$ & 5.86 & 2 \\
\hline
\end{tabular}

\section{Conclusion}

Competition is a key word in the deregulated market and it is in close association with the economy. The positive values of NPV indicate the economic viability of investment planning when CCHPs are deployed optimally in the system and their use reaches economies of scale.

In this paper, a value-based planning method for CCHP placement has been proposed based on the energy hub concepts.

The proposed method, determines the best operational point of energy hub of CHP, absorption chiller, auxiliary boiler and heating storage devices with maximum net benefit. To solve the problem, the GAMS software is employed. After finding the optimal energy hub elements operation, by employing COMFAR III, financial parameters are calculated. Test results show that CCHP installation is one of the best methods to decrease the power cost overtly.

Future work may be extended with benefits, such as the type of manufacturer, type of technology, policies of the local utility, and seasonal effect on demand and load growth rate.

\section{Nomenclature}

$\mathrm{P}_{\mathrm{e}} \quad$ Purchased electricity [kWh]

$\mathrm{P}_{\mathrm{g}} \quad$ Purchased natural gas $[\mathrm{kWh}]$

$\mathrm{P}_{\mathrm{gM}}$ Maximum purchased natural gas [kW]

$\mathrm{P}_{\mathrm{gm}} \quad$ minimum purchased natural gas $[\mathrm{kW}]$

$\mathrm{P}_{\mathrm{eM}} \quad$ Maximum purchased electricity [kW]

$\mathrm{P}_{\mathrm{em}} \quad$ Minimum purchased electricity [kW]

$\gamma \quad$ Dispatched factor for natural gas inlet

$\alpha \quad$ Dispatch factor for auxiliary boiler

$\beta \quad$ Dispatch factor for CHP

$\mathrm{kk} \quad$ Exported electricity to the grid [kWh]

$\mathrm{P}_{\mathrm{seM}}$ Maximum exported electricity [kWh]

$a_{\mathrm{k}} \quad$ annual net cash flow

$\chi_{e} \quad$ price of carbon for using electricity as energy hub input $[\$ / \mathrm{kWh}]$

$\chi_{\mathrm{g}} \quad$ price of carbon for using natural gas as energy hub input $[\$ / \mathrm{kWh}]$

$\mathrm{g}(\mathrm{n})$ natural gas price $[\$ / \mathrm{kWh}]$

e(n) electricity price $[\$ / k W h]$

DCF Discounted Cash Flow

IRR Internal Rate of Return

NPV Net present value 
DPP Dynamic payback period

$\eta_{e e} \quad$ Transformer efficiency

$\eta_{g h}^{B} \quad$ Boiler efficiency

$\eta_{g e}^{C H P} \quad$ Electrical efficiency of CHP

$\eta_{g h}^{C H P} \quad$ Heating efficiency of CHP

$\eta^{\text {chiller }}$ Efficiency of the absorption chiller

\section{Acknowledgment}

The authors would like to thank the Elite National Foundation for financial support during this research.

\section{References}

[1] M. Rabinowitz, "Power Systems of the Future. I," IEEE Power Engineering Review, Vol. 20, No. 1, 2000, pp. 5- 16. doi:10.1109/39.814649

[2] C. Mitchell, "The value of distributed generation-policy implications for the UK". IEE Coll Econ Embed Generat 1998:1/1-1/11.

[3] Jen-Hao Teng , Yi-Hwa Liu , Chia-Yen Chen and Chi-Fa Chen,"Valuebased distributed generator placements for service quality improvements", Electrical Power and Energy Systems Vol. 29, No. 3, 2007, pp. 268-274. doi:10.1016/j.ijepes.2006.07.008

[4] M. Geidl, "Integrated modeling and optimization of multicarrier energy systems“, Power Systems Laboratory, ETH Zurich, 2007

[5] A. Sheikhi, M. Khosravi, B. Mozafari and A.M. Ranjbar, "Natural Gas Pricing Policy to Have Maximally Peak Shaving", ICREPQ, Spain, 2011

[6] R. Billinton, and R. N. Allen, "Reliability evaluation of engineering systems, concept and techniques" $2^{\text {nd }}$ ed. , New York, Plenum press 1992

[7] R. Graham and W. Chow, "Technical and Economic As- sessment of Combined Heat and Power Technologiesfor Commercial Customer Applications", EPRI Project Manager, 2003.

[8] Heeijn Cho, Rogelio Luck a, Sandra D. Eksioglu b, Louay M. Chamra," Cost optimized real time operation of CHP system", Energy and Buildings, Vol. 41, No. 4, 2009

[9] A. Sheikhi, B. Mozafari and A.M. Ranjbar "CHP Optimize selection Methodology for a Multicarrier Energy System", Power Tech Conference, Norway, 2011

[10] A. R. Abdelaziz and W. M. Ali, "Dispersed generation planning using a new evolutionary approach," presented at the IEEE Bologna PowerTech Conf., Bologna, Italy, Jun. 23-26, 2003.

[11] R. Dugan, T. E. McDermott and G. J. Ball, "Planning for distributed generation”, IEEE Ind. Appl. Mag., vol. 7, no. 2, pp. 80-88, Mar./Apr. 2001.

[12] H. M. Groscurth, T. Bruckner and R. Kümmel, "Modeling of energy service supply system", Energy, vol. 20, no. 9, pp. 941-958, 1995.

[13] I. Bouwmans and K. Hemmes, "Optimising energy systems-Hydrogen and distributed generation”, 2nd Int. Symp. Power System Market Aspects, Stockholm, 2002

[14] R. H. Lasseter and P. Piagi, "Microgrid: A conceptual solution", in Proc. IEEE 35th Annu. Power Electronics Specialists Conf. (PESC), Aachen, Germany, 2004.

[15] A. Sheikhi, A. M. Ranjbar, M. Mahmoody and F. Safe, "CHP Optimize Selection Methodology for an Energy Hub System", 2011 10th International Conference on En-vironment and Electrical Engineering, Rome, 8-11 May 2011, pp. 1-5.

[16] A. Sheikhi, B. Mozafari and A. M. Ranjbar, "CHP Opti-mize Selection Methodology for a Multicarrier Energy System", IEEE PowerTech Conference, Trondheim, 19-23 June 2011, pp. 1-7.

[17] A. Sheikhi, A.M. Ranjbar, H. Oraee and A.R. Moshari, "Optimal operation and size for an energy hub with CCHP", Energy and Power Engineering Journal (2011).
[18] Bjorn Rolfsman, " $\mathrm{CO} 2$ emission consequences of energy measures in buildings", Energy and Building, Vol.37, No. 12, 2002

[19] D.G. Newnan, T.G. Eschenbach and J.P. Lavelle, Engineering Economic Analysis, Ninth edition, 2004.

[20] M.Y. Khan, Theory \& Problems in Financial Management, McGraw Hill Higher Education, 1993.

[21] M.A. Main, Project Economics and Decision Analysis. Volume I: Deterministic Models, 2002.

[22] D\&R, Buildings Energy Data Book, D\&R International, Ltd., 2009.

[23] A. Sheikhi, et al., "CHP optimized selection methodology for a multicarrier energy system", International of Review Electrical Engineering (I.R.E.E) 6 (4) (2011).

[24] American Society of Heating Refrigerating and Air-Conditioning Engineers, ASHRAE Handbook-HVAC Systems and Equipment, 2009.

[25] H. Li, et al., "Energy utilization evaluation of CCHP systems", Energy and Building 38 (3) (2006).

[26] H. Cho, "Evaluation of CCHP systems performance based on operational cost primary energy consumption, and carbon dioxide emission by utilizing an optimal operation scheme", Applied Energy 86 (2009) 2540-2549.

[27] M. Stadler, et al., The $\mathrm{CO} 2$ reduction potential of combined heat and power in California's commercial buildings, Clean Tech Law \& Business journal 517(2009). 